\title{
Fatores de sucesso e fracasso em projetos de base tecnológica no contexto do PII
}

Jordana Torres Machado

jordana.t.machado@gmail.com

Luciana Paula Reis

lucianapaula@deenp.ufop.br

Sergio Evangelista Silva

sergio@deenp.ufop.br

\section{RESUMO}

Entre as diversas ações que buscam alavancar a inovação e desenvolvimento tecnológico está a promoção de empresas de base tecnológica (EBTs). Assim, esta pesquisa tem como objetivo identificar as decisões relevantes para a evolução do projeto ao longo do processo de planejamento do produto e do negócio, como também a identificação dos fatores que conduzem ao sucesso e, até mesmo, o fracasso desses projetos. Este estudo será realizado a partir de análises dos relatórios do PII oriundos da UFMG e também através de um estudo comparativo entre os projetos, utilizando, para isso, a estratégia metodológica da análise de conteúdo. o Programa de Incentivo à Inovação (PII) é um programa do governo que busca permitir que projetos de pesquisa aplicada se transformem em inovações tecnológicas, promovendo o desenvolvimento regional $e$ facilitando a integração entre a academia e o setor empresarial. Como resultado da pesquisa, espera-se a identificação dos fatores críticos para o sucesso dos projetos dos PIIs ao longo do PPNeg (Processo de Planejamento do Negócio) que contempla três importantes perspectivas: a institucional, o modelo de negócio e os recursos (financeiro e humano/social). Este estudo pode servir como elemento de apoio à elaboração $e$ implantação desses tipos de projetos em universidades.

Palavras-chave: Processo de Planejamento Tecnológico, Plano Tecnológico, Processo de Planejamento do Negócio, Empresas Nascentes de Base Tecnológica.

\section{Success and failure factors in technological base projects in the context of PII (Programa de Incentivo a Inovação)}

\begin{abstract}
Among the several actions which seek to leverage technological innovation and development is the promotion of the technology based companies (TBCs). Thus, this research aims to identify the relevant decisions for the project's progress throughout the product and business planning process, as well as the identification of the factors that lead to success and even failure of these projects. This study will be developed based on the PII report analysis coming from UFMG and through a comparative study between the projects, using for this the methodological content analysis strategy. PII is a government program which seeks to allow that applied research projects be transformed into technological innovations, promoting the regional development and facilitating the integration between the academy and the business sector. As a research result, it is expected the identification of critical factors for the success of the PII projects during the business planning process (BPP), which contemplates three important perspectives related to: the institution, the business model, and the resources (financial and human/social). This study may serve as a supporting element to elaboration and implantation of these kinds of projects in universities.
\end{abstract}

Key words: Technological Base Projects; Technological Planning; Business Planning Process; Technological Based New Enterprises. 


\section{Referencial teórico}

\section{Introdução}

A inovação tecnológica consiste em um dos elementos fundamentais no desenvolvimento das sociedades capitalistas mais avançadas (GROSSMAN, 1993) e da competitividade da empresa global (MAHMOOD; MITCHELL, 2004). Em termos práticos, a inovação tecnológica ocorre pelo surgimento de novos produtos e processos. Determinado processo de inovação normalmente se consolidará como produto no mercado, à medida que permite a execução de atividades já existentes com maior eficiência e, ou, introduza funcionalidades até então indisponíveis no mercado.

O sucesso da inovação, de forma que apresenta contribuição e relevância social por meio do desenvolvimento de produto e negócio, está relacionado aos fatores impeditivos $\mathrm{e}$ impulsionadores que coloca a inovação como grande desafio, posto que esta área ainda não está consolidada na literatura.

O objetivo desta pesquisa é identificar, assim, as decisões relevantes para a evolução do projeto ao longo do processo de planejamento do produto e do negócio, como também a identificação dos fatores que conduzem ao sucesso e, até mesmo, o fracasso. Do ponto de vista lógico, o sucesso ou malogro de um projeto do tipo PII estará atrelado à proposta inicial e, ou, ao processo de desenvolvimento da proposta. Deduz-se que o sucesso de um projeto de inovação tecnológica é resultado do sucesso tanto da fase de elaboração da proposta, ou seja, que esta seja viável e factível, quanto da fase de desenvolvimento.

Ressaltando os fatores críticos para $o$ sucesso (FCSs) de projetos de inovação tecnológica, especificamente os Programas de Incentivo à Inovação (PIIs), têm-se as seguintes contribuições: prover referência para a avaliação de PIIs, permitindo um processo de seleção de projetos que minimizem os riscos e aumentem as chances de benefícios, empregando, assim, da melhor forma, recursos públicos de incentivo à inovação; servir como referência para pesquisadores e técnicos que desejam empreender iniciativas de produtos e, ou, empresas de base tecnológica, aumentando suas chances de sucesso; contribuir para a literatura de inovação tecnológica; e identificar fatores essenciais para projetos desta natureza.

\subsection{O contexto de EBTs de OA}

A partir da segunda metade do século XX, a inovação tecnológica ganha status de política de Estado, sendo reconhecida por governos como elemento fundamental no desenvolvimento econômico e no fortalecimento geopolítico de um país. Pelo exposto, pode-se dizer que, ao longo do tempo, a propriedade cumulativa da ciência e do aparato técnico torna a inovação tecnológica cada vez mais um fenômeno sistêmico (GOODAL et al., 2011; LAHIRI, 2010; PHELPS, 2010; DESHPANDÉ et al., 1993). Além dos aspectos mercadológicos (MENGUNC; AUH, 2006; HAN et al., 1998; BOLWINJN; KIMPE, 1990), um processo fundamental no desenvolvimento de inovações tecnológicas é o seu processo de geração, que normalmente contará com uma equipe de desenvolvedores e um aparato de recursos para a sua realização. Considerando Simon (1970), é possível concluir que é mais provável que produtos de inovação sejam gerados de modo sistemático em ambientes institucionais adequadamente estruturados e desenvolvidos do que em ambientes incipientes.

O desenvolvimento de uma nova tecnologia consiste em um processo de alto risco (FREMAN; SOETE, 1997). Os riscos podem ser classificados em duas naturezas principais: os riscos envolvidos com o processo de geração da nova tecnologia, sendo este de natureza técnica e organizacional. Neste caso, há a possibilidade de os objetivos inicialmente propostos no início de um projeto de inovação tecnológica não serem atingidos, devido a fatores como ausência de recursos, deficiências de origem técnica, organizacionais, entre outras. Todavia, ultrapassada a primeira etapa, a da geração efetiva de uma inovação tecnológica, o produto ou processo gerado estará sujeito ao segundo tipo de risco, o chamado risco de mercado. Pode-se observar em Freman e Soete (1997) que, muitas vezes, uma inovação tecnológica nem sempre é assimilada pelo mercado no momento desejado. Este projeto estará tratando, principalmente, dos fatores associados ao primeiro tipo de risco, ou seja, aos elementos essenciais para o sucesso da geração de inovações tecnológicas.

As inovações tecnológicas podem culminar com a geração de spin-offs acadêmicos ou EBTs de $\mathrm{AO}$, que são importantes formas de geração de valor e de desenvolvimento social e tecnológico. 
Shane (2004) e Roberts (1991) definiram spin-off acadêmico como uma nova empresa, criada para explorar a propriedade intelectual desenvolvida nas instituições acadêmicas, fundadas por pessoas que estudam ou trabalham na universidade.

O surgimento de um spin-off é caracterizado por fatores como as características individuais dos envolvidos, a configuração organizacional da empresa envolvendo os recursos necessários, a influência dos fatores externos advindos do ambiente e o próprio processo de desenvolvimento do negócio, além do contexto sociocultural da universidade (O'SHEA, 2007). Wright (2008), em seu estudo de geração de spin-offs no contexto europeu, percebeu que o suporte das universidades na promoção das tecnologias geradas pelos pesquisadores é fundamental para que elas possam sair da inércia em um menor tempo ao mercado e, com isso, atuar tanto nos mercados nacionais quanto internacionais.

Um princípio útil para a busca de fatores fundamentais em determinado processo está no princípio dos Fatores Críticos do Sucesso, conceito lançado por Rockart (1979). Inicialmente proposto para a identificação das informações mais relevantes para os gestores de empresas, este é um importante instrumento que também pode ser utilizado para identificar quais são os fatores elementares para se atingir determinado objetivo. $\mathrm{O}$ princípio subjacente dos FCSs é que, embora toda atividade ou empreendimento estejam associados a uma grande quantidade de fatores, pequena parcela destes será realmente determinante para o seu sucesso. Essa abordagem considera, intrinsecamente, a escassez de recursos de diferentes naturezas, e a consequente necessidade de empregá-los da maneira mais eficiente possível. Com efeito, é importante a identificação de FCSs para projetos de variadas naturezas, inclusive os de inovação tecnológica. Apresentados os conceitos principais acerca de projetos e inovação tecnológica e dos FCSs nas próximas seções, são apresentados os aspectos metodológicos do projeto.

\subsection{As perspectivas que influenciam a geração de EBTs}

Como forma de identificar os FCSs, pode-se classificar, segundo as perspectivas que influenciam o processo de geração de EBTs, desde o seu nascimento até o seu desenvolvimento, em três perspectivas (MUSTAR, 2006): i) perspectiva baseada em recursos, ii) perspectivas de modelos de negócios e iii) perspectivas da relação institucional.

A perspectiva baseada em recursos, segundo Barney (1991), é subdividida em quatro dimensões: recursos técnicos, humanos, sociais/organizacionais e financeiros. A primeira refere-se ao grau de inovação, ao domínio tecnológico e ao tipo de tecnologia da empresa e de recursos físicos. Segundo Heirman e Clarysse (2004), os recursos técnicos incluem a planta e os equipamentos e a localização geográfica, além do seu acesso às matérias-primas. A segunda dimensão, recursos humanos, refere-se às características da equipe empreendedora e suas experiências. Para EBTs, o empreendedor-pesquisador é o mais importante, se não o único capital humano presente na empresa (VAN DE VEM et al., 1984). A terceira, recursos social e organizacional, são os sistemas, as rotinas e os relacionamentos incrustados na empresa e em toda a sua rede social. Eles representam a maneira pelas quais as EBTs combinam e transformam as tecnologias em produtos comerciais (GALUNIC; RODAN, 1998). A última dimensão refere-se ao recurso financeiro disponível para $\mathrm{o}$ empreendimento, que incluem todos os diferentes recursos monetários que as firmas podem usar como: capital advindo do empreendedor, de privaty equities, de devedores, financiamentos ou até mesmo a disponibilidade própria. Esses recursos financeiros são importantes nas fases mais prematuras do desenvolvimento da EBT, uma vez que auxilia na definição das estratégias futuras para o novo empreendimento (LEE et al., 2001).

A perspectiva baseada em modelos de negócios aborda as estratégias de atuação, identificação do segmento de mercado, posição na cadeia de valor para estimar os lucros e custos da empresa e para aumentar o valor percebido. Essa perspectiva preocupa-se em como transformar em valor comercial as tecnologias e os conhecimentos das universidades.

Por fim, a perspectiva institucional demonstra a influência da cultura universitária, infraestrutura disponível, a capacidade de investimento, incentivo governamental e apoio das incubadoras e parques tecnológicos na concretização e consolidação de uma EBT. Para Heirman e Clarysse (2004), os fatores ambientais e contextuais da universidade influenciam o processo empreendedor por ser o berço da EBT de OA e por direcionar os avanços tecnológicos da estrutura industrial. 
A Figura 1 apresenta a relação dessas três perspectivas com o Processo de Planejamento do Negócio (PPN). Conforme mencionado, o PPN é um processo de integração da TPM, sendo este influenciado pelo ambiente e contexto institucional, pelas características humanas e sociais da ENBT, pelos recursos disponíveis e, também, pelas diferentes possibilidades de articulação desses TPMs para a geração de valor comercial, denominado Modelo de Negócio.

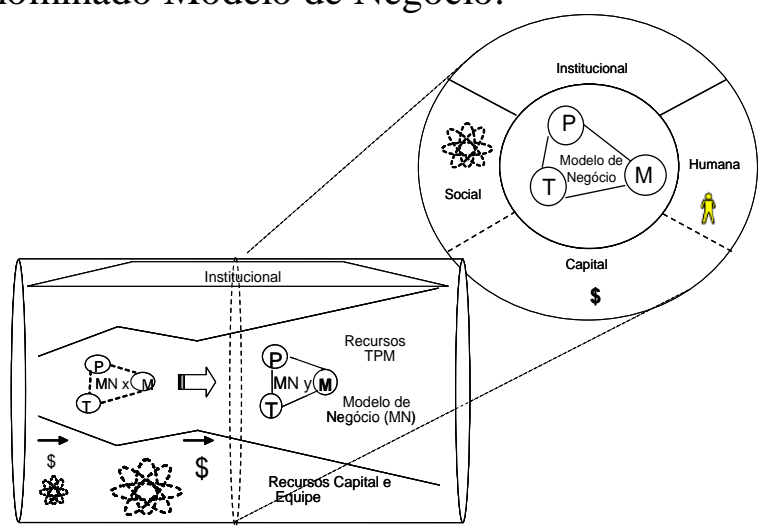

Figura 1 - Influência das Perspectivas Institucional, Modelo de Negócios e Recursos no PPN

Fonte: Os autores.

\section{Metodologia}

Esta pesquisa foi desenvolvida com base nas análises dos relatórios do PII oriundos da UFMG e através de um estudo comparativo entre os projetos desenvolvidos no ambiente da universidade, utilizando para isso a estratégia metodológica da análise de conteúdo. Foram comparados 10 projetos de pesquisas vinculados ao PII, programa do governo para incentivar o surgimento de EBTs e o desenvolvimento de produtos comerciais a partir das tecnologias do ambiente acadêmico.

Para identificar os fatores de sucesso e fracasso no surgimento dos negócios no PII, os relatórios foram elaborados por meio da análise de conteúdo que, segundo Vergara (2005, p. 15), essa é uma técnica "para o tratamento de dados que visa identificar o que está sendo dito a respeito de determinado tema", que neste artigo se refere às dinâmicas subjacentes ao desenvolvimento de tecnologias e aos negócios tecnológicos nos projetos do PII-MG. A análise de conteúdo compreende três etapas básicas: (a) pré-análise; (b) exploração do material; e (c) tratamento dos dados e interpretação. A pré-análise refere-se à seleção do material propriamente dito (BARDIN, 1977). Salienta-se que foram selecionados e explorados apenas os conteúdos alinhados com a temática em estudo, e os relatórios do PII apresentam-se mais amplos e dispõem de informações que extrapolam a aplicação a eles conferida nesta investigação.

\section{Resultados}

\subsection{As etapas e pontos de decisões para as fases de integração do TPM e desenvolvimento do negócio}

Com o intuito de desdobrar as principais atividades e pontos-chave de decisões para o desenvolvimento do projeto e do negócio e, com isso, facilitar a orientação dos pesquisadoresempreendedores, foi elaborada a Tabela 1. Por meio da identificação das diversas etapas de desenvolvimento do produto e do negócio, torna-se possível identificar os FCSs.

\section{Fase 1 e Decisão 1}

Todas as empresas que serviram como objeto de trabalho para os autores deste artigo surgiram de pesquisas realizadas dentro das universidades, principalmente por professores e alunos de pós-graduação. Os projetos de pesquisa possibilitaram a geração de publicações acadêmicas e patentes que podem ser exploradas pelas ENBTs. Ao mesmo tempo, as futuras empresas podem enriquecer a pesquisa aplicada para mestrandos e doutorandos da academia. Nesta fase, então, o pesquisador, ao explorar o referencial teórico, identifica uma oportunidade para desenvolver uma nova tecnologia a partir da ciência. Conforme mencionado, esse input pode ser tanto externo quanto interno.

No primeiro portal de decisão, os empreendedores devem verificar se aquela tecnologia vislumbrada realmente satisfaz uma necessidade de mercado, ou seja: a tecnologia, realmente, representa uma inovação? Ou, pelo menos, promove substituição de importações? Nesse momento, também é importante que o empreendedor tenha uma ideia clara quanto à necessidade de parcerias. Caso essa necessidade se mostre explícita, torna-se importante verificar se os potenciais parceiros e fornecedores se encontram disponíveis no mercado. 


\section{Fase 2 e Decisão 2}

Nesse momento, busca-se materializar a ciência em uma tecnologia que possua diferenciação competitiva. Nessa fase são desenvolvidos o princípio da tecnologia e o teste de sua funcionalidade para a identificação dos potenciais gargalos. O questionamento realizado para tomar a decisão de continuar ou abortar o projeto é com relação à definição do conceito da tecnologia. $\mathrm{O}$ pesquisador tem que entender o que ele desenvolveu em termos de tecnologia, que é o potencial desta em melhorar os produtos, processos e serviços do mercado. Além disso, o pesquisador tem que possuir provas ou indícios suficientes de que a tecnologia é válida e funciona.

\section{Fase 3 e Decisão 3}

Nesse estágio do desenvolvimento são identificadas e priorizadas as várias aplicações da tecnologia. É desenvolvido o protótipo laboratorial do produto e, ou, a produção laboratorial. Os pesquisadores-empreendedores iniciam a transformação da ideia inicial, ou visão empreendedora, em um negócio semiestruturado. Os Centros de Transferência Tecnológica (CTT) e incubadoras de empresas exercem papel fundamental nessa estruturação de oportunidade, uma vez que auxiliam o empreendedor quanto à proteção intelectual e ao processo de conhecimento do potencial de mercado a ser atingido.

Outra atividade relevante nesta fase é a realização do Estudo de Viabilidade Técnica, Econômica, Comercial e de Impacto Ambiental e Social (EVTECIAS). Este estudo, preliminar, servirá como fonte para organização de dados relevantes ao nascimento da empresa. Também é essencial que, nesse estágio, o pesquisador faça uma análise de todos os possíveis produtos que a base tecnológica pode gerar. Para tanto, pode-se utilizar a ferramenta Gestão da Plataforma. Por fim, esta fase é marcada pela necessidade de interação do empreendedor com fornecedores, parceiros e potenciais clientes.

Esse momento de decisão está ligado à necessidade de comprometimento do empreendedor com a geração da empresa. Por se tratar de pesquisadores com perfil acadêmico, há relutância deles quanto a preterir suas atividades de pesquisa em favor de tarefas jamais enfrentadas, ligadas à abertura de uma empresa. Para superação desse gate, faz-se necessário que $\mathrm{o}$ pesquisador- empreendedor tenha transformado visão em oportunidade estruturada. Essa oportunidade é demonstrada pela análise do EVTECIAS. Além disso, ele deve garantir que o protótipo do produto funcione conforme o planejado e em condições controladas no laboratório e que a tecnologia resolva um problema de mercado.

\section{Fase 4 e Decisão 4}

Nesta fase de desenvolvimento é importante que $o$ pesquisador-empreendedor inicie a implantação e consolidação das estratégias estabelecidas. Além disso, o momento é crucial para a tomada de decisões relativas a recursos financeiros e humanos. Ou seja, o pesquisador, inexperiente na área, deve buscar capital intelectual e recursos monetários necessários para o desenvolvimento da empresa. Nessa etapa é estudada a cadeia de valor para facilitar a prospecção de alternativas de modelos de negócios. Durante essa etapa são realizados os testes da funcionalidade do protótipo em condições não controladas, além da produção em escala-piloto. Busca-se incorporar a voz do cliente no produto, além do seu registro e certificação.

O empreendedor, nesse momento, deve ter superado as dificuldades de obtenção de recursos e ter fortes indícios de que o modelo de negócio escolhido, com a consolidação de estratégias, possui alto potencial de retorno. Nessa decisão, o empreendedor deve ter certeza de que conta com os recursos necessários para abertura da empresa e início da comercialização. Ou seja, a empresa deve estar apta a lidar com a dinamicidade do mercado e ter acesso a capital intelectual nas áreas administrativa, contábil e jurídica. Para evoluir nas fases do Processo de Planejamento de Negócio, é necessário que o pesquisador-empreendedor defina como explorar essa tecnologia e se irá transferir para a própria empresa (empreender) ou transferir para uma empresa já existente no mercado. E, para facilitar essa negociação, a equipe deverá traçar a estratégia de comercialização mais adequada.

\section{Fase 5}

Nesta última fase, os empreendedores devem "cortar o cordão umbilical" com as universidades sem, no entanto, perder o vínculo com elas. Espera-se alcançar a autossuficiência. Além disso, é importante que se estruturem os pontos de venda, canais de distribuição e uma estratégia de expansão para a empresa, com o lançamento de novos produtos para mercados 
distintos. Esta fase representa o estágio de início das comercializações e de consequente geração de retorno via oferta de produtos aos clientes. A dificuldade gerencial dos empreendedores e a dinamicidade de relações com fornecedores $\mathrm{e}$ clientes marcam esta fase do desenvolvimento.

\subsection{Influências das Perspectivas Institucionais e Recursos (Financeiro e Equipe) para o desenvolvimento do PPtec}

Entre as várias perspectivas citadas por Mustar (2006) e que diferenciam as EBTs, o pictograma do Processo de Planejamento de Negócio apresentado neste capítulo trabalha mais fortemente a perspectiva dos recursos, principalmente a dimensão da tecnologia, que aqui será trabalhada como a integração TPM ao longo das fases do PPNeg. Além disso, por apresentar as fases do desenvolvimento do negócio, ele acaba por englobar a perspectiva de Modelo de Negócio, uma vez que, durante a estruturação das EBTs, é importante definir qual a estratégia mais adequada para explorar o produto tecnológico desenvolvido. A definição do modelo de negócio com potencial de retorno está associada à maneira como os recursos são integrados (recursos TPM, Financeiro e Humano/Social), sendo influenciados pelo ambiente onde a empresa está inserida, como apresentado na Figura 13.

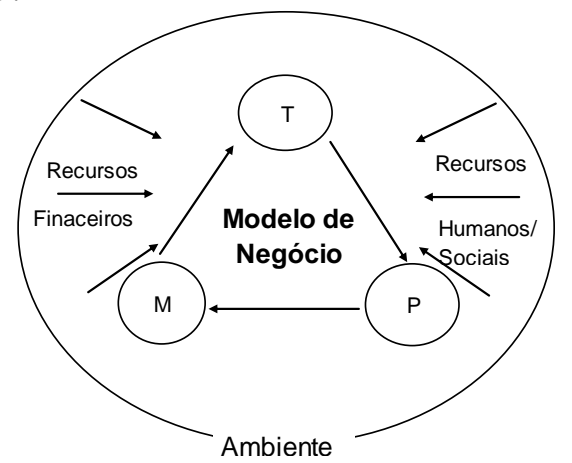

Figura 2 - Fatores que determinam a escolha do modelo de negócio

Fonte: Os autores.

Então, para entender as relações das dimensões de recursos (financeiro, humano/social) e a perspectiva institucional com a integração TPM e o modelo de negócio, foram desenvolvidas matrizes que apresentam as fases do TPM e quais as necessidades financeiras e humanas e de apoio institucional que a empresa carece em cada uma dessas fases. Vale ressaltar que alguns desses recursos podem estar ligados a mais de uma fase, e eles são determinantes no progresso do empreendimento ao longo dos vários estágios de desenvolvimento. $\mathrm{O}$ cumprimento dessas necessidades refletem os fatores de sucesso e fracasso dos projetos. 


\begin{tabular}{|c|c|c|c|c|c|c|c|c|c|c|c|c|c|c|c|}
\hline \multicolumn{11}{|c|}{ Desenvolvimento do Projeto } & \multicolumn{5}{|c|}{ Desenvolvimento do Negócio } \\
\hline \multirow{2}{*}{ 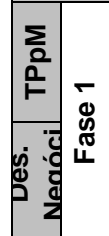 } & \multirow{2}{*}{\begin{tabular}{|c|}
$\begin{array}{c}\text { Fase de } \\
\text { Pesquisa } \\
\text { Científica }\end{array}$ \\
$\begin{array}{l}\text { Fase de } \\
\text { Pesquisa }\end{array}$ \\
\end{tabular}} & \multirow{2}{*}{ Decisão 1} & & \multirow{2}{*}{$\begin{array}{c}\begin{array}{c}\text { Fase de } \\
\text { Tecnologia } \\
\text { Embrionária }\end{array} \\
\begin{array}{c}\text { Fase de } \\
\text { Pesquisa }\end{array}\end{array}$} & \multirow{2}{*}{$\begin{array}{l}\text { Decisão } \\
2\end{array}$} & & Fase Laboratorial & \multirow{2}{*}{ Decisão 3} & & \multicolumn{2}{|c|}{ Fase Pré-Comercial } & \multirow{2}{*}{ Decisão 4} & \multirow{2}{*}{ 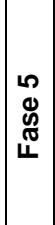 } & \multicolumn{2}{|c|}{$\begin{array}{c}\text { Fase } \\
\text { Comercialização }\end{array}$} \\
\hline & & & & & & & $\begin{array}{c}\text { Fase de Estruturação da } \\
\text { Oportunidade }\end{array}$ & & & $\begin{array}{c}\text { Fase de } \\
\text { Estrut. da } \\
\text { Oportunid }\end{array}$ & Fase Protofirm & & & $\begin{array}{r}\text { Fase } \\
\text { Start-up }\end{array}$ & $\begin{array}{l}\text { Fase } \\
\text { ENBT }\end{array}$ \\
\hline 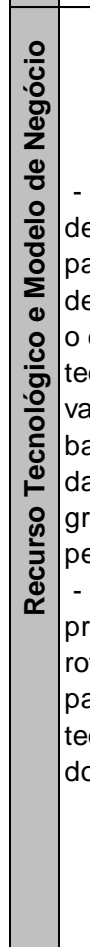 & $\begin{array}{l}\text { Identificação } \\
\text { e oportunidade } \\
\text { ara } \\
\text { esenvolviment } \\
\text { de uma } \\
\text { cnologia de } \\
\text { anguarda com } \\
\text { ase no estado } \\
\text { a arte e } \\
\text { rupos de } \\
\text { esquisa. } \\
\text { Identificacãao } \\
\text { reliminar da } \\
\text { ta tecnológica } \\
\text { ara a (s) } \\
\text { ccnologia (s) } \\
\text { o laboratório? }\end{array}$ & $\begin{array}{l}\text { - A } \\
\text { oportunidad } \\
\text { e se } \\
\text { configura } \\
\text { em uma } \\
\text { tecnologia } \\
\text { de } \\
\text { vanguarda } \\
\text { com grande } \\
\text { valor para a } \\
\text { sociedade? }\end{array}$ & \multicolumn{2}{|c|}{\begin{tabular}{|l|} 
- Desenvolvimento \\
do princííio da \\
tecnologia \\
- Identificação das \\
tecnologias chaves e \\
complementares \\
- Identificaçãa do \\
diferencial \\
competitivo da \\
tecnologia \\
- Identificação dos \\
gargalos \\
tecnologicos \\
- Identificação da \\
plataforma \\
tecnológica
\end{tabular}} & $\begin{array}{l}\text { - Possui } \\
\text { a } \\
\text { definição } \\
\text { do } \\
\text { conceito } \\
\text { da } \\
\text { tecnologi } \\
\text { a? }\end{array}$ & \multicolumn{2}{|c|}{\begin{tabular}{|l|} 
- Desenvolvimento do \\
protótipo da tecnologia \\
- Desenvolvimento da \\
produção em escala \\
laboratorial (gramas do \\
produto). \\
- Identificação das aplicações \\
(estruturação das plataformas \\
de produto) \\
- Priorização da aplicação \\
- Desenvolvimento do protótipo \\
do produto \\
- Identificação da estratégia de \\
proteção da tecnologia \\
- Inicialização da proteção \\
- Identificação dos recursos \\
necessários para o \\
desenvolvimento e produção \\
do produto \\
- Estudo da plataforma \\
potencial de produtos \\
(produtos derivativos) \\
- Elaboração do EVTECIAS
\end{tabular}} & \begin{tabular}{|l|} 
- O Protótipo funciona \\
nas condições \\
laboratoriais controladas \\
e consegue-se \\
repetições desses \\
resultados? \\
- O desempenho obtido \\
está dentro dos padrões \\
esperados (desempenho \\
superior às soluções do \\
mercado ou \\
desempenho similar e/ou \\
a um preço mais \\
acessível)? \\
- A tecnologia/produto \\
satisfaz adequadamente \\
um problema de \\
mercado? \\
- A análise do EVTECIAS \\
demonstra uma boa \\
oportunidade de \\
negócio? \\
- A plataforma de \\
produtos possui \\
potencial de retorno \\
satisfatório?
\end{tabular} & \multicolumn{3}{|c|}{$\begin{array}{l}\text { - Realização de testes para obter } \\
\text { repetividade dos resultados dos } \\
\text { experimentos em condições não- } \\
\text { controladas. } \\
\text { - Desenvolvimento da produção em } \\
\text { escala piloto (Kg do produto) } \\
\text { - Iniciação do registro e certificação } \\
\text { do produto } \\
\text { - Desenvolvimento da produção em } \\
\text { toneladas } \\
\text { - Adequação do protótipo para } \\
\text { incorporar a voz do cliente (além de } \\
\text { desempenhar tecnicamente a } \\
\text { função, o protótipo deve possuir um } \\
\text { design adequado e atender as } \\
\text { necessidades do cliente) } \\
\text { - Definição do PTP } \\
\text { - Estudo da cadeia de valor na qual } \\
\text { a tecnologia está inserida } \\
\text { - Prospecção das alternativas de } \\
\text { modelos de negócios } \\
\text { - Definição das estratégias de } \\
\text { comercialização } \\
\text { - Elaboração do Plano Tecnológico }\end{array}$} & $\begin{array}{l}\text { - O Protótipo } \\
\text { funciona em } \\
\text { condições não- } \\
\text { controladas? } \\
\text { - Consegue-se uma } \\
\text { de maior escala de } \\
\text { produção sem alterar } \\
\text { as características do } \\
\text { produto? } \\
\text { - Protótipo foi } \\
\text { validado pelo } \\
\text { mercado? } \\
\text { - Existe algum } \\
\text { modelo de negócio } \\
\text { com potencial de } \\
\text { retorno satisfatório? } \\
\text { - A estratégia de } \\
\text { comercialização está } \\
\text { adequada? }\end{array}$ & \multicolumn{3}{|c|}{$\begin{array}{l}\text { - Comercialização do } \\
\text { produto } \\
\text { - Identificação dos } \\
\text { pontos de venda e } \\
\text { canais de distribuição } \\
\text { - Identificação de } \\
\text { nichos de mercado } \\
\text { - Desenvolvimento da } \\
\text { plataforma de } \\
\text { produtos para } \\
\text { aumentar o portfolio } \\
\text { da empresa } \\
\text { - Definição da } \\
\text { estratégia de } \\
\text { expansão } \\
\text { Elaboração do Plano } \\
\text { de Negócio Estendido }\end{array}$} \\
\hline
\end{tabular}




\subsubsection{Recursos financeiros}

Os recursos financeiros referem-se, usualmente, ao montante e tipo de financiamento de uma EBT de OA. Após a identificação da oportunidade de negócio, seja através de uma lacuna na bibliografia ou de uma necessidade explicitada pelo mercado, tem-se um momento crucial de decisão para os pesquisadores: a equipe possui o capital necessário para iniciar o desenvolvimento da tecnologia? Existem fontes de recursos financeiros acessíveis? As respostas a esses questionamentos são responsáveis por definir se os pesquisadores começarão a desenvolver a tecnologia ou se a falta de capital forçará o "congelamento" daquela ideia inicial.

Conforme pode ser visto na Figura 14, após a identificação dos recursos para o desenvolvimento inicial da tecnologia, já na fase pré-comercial, fazse necessária a obtenção de capital para a construção de planta-piloto e de protótipos funcionais do produto. Vale destacar que, durante as fases do desenvolvimento do projeto (Tecnologia Embrionária, Fase Laboratorial e Fase PréComercial), a necessidade de recursos financeiros para o desenvolvimento da tecnologia, como matérias-primas e equipamentos e insumos laboratoriais, mostra-se latente.

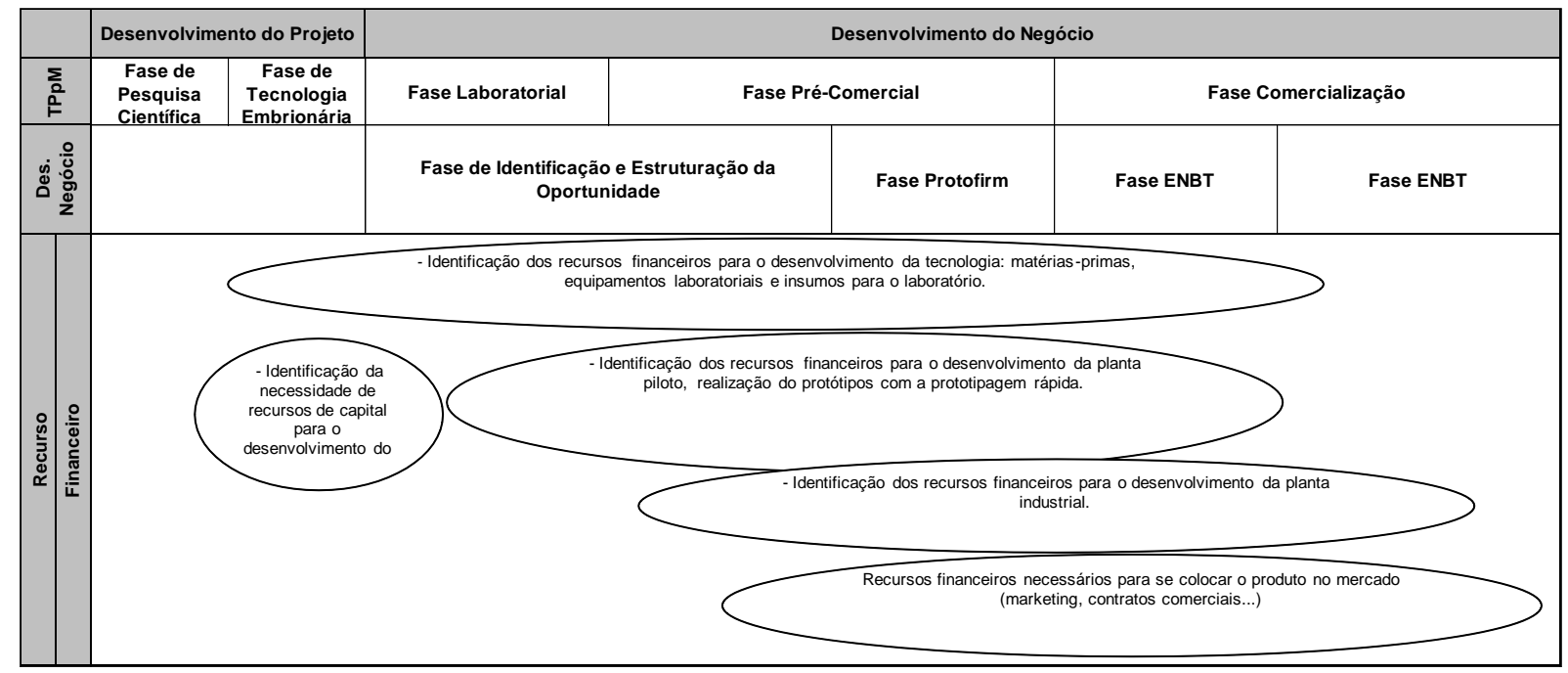

Figura 3 - Influência da dimensão financeira no processo de planejamento de negócio

Por fim, durante a fase comercial os últimos recursos financeiros (quase sempre de maior montante) são buscados pelos empreendedores. Tais recursos são utilizados para a construção de uma planta em escala industrial e, então, para a produção e lançamento do produto. A falta ou atraso na liberação das verbas para os projetos são fatores que podem ser destacados como dificuldades para o desenvolvimento das EBTs. As questões financeiras impedem o cumprimento do cronograma de execução previsto no escopo do projeto que seja realizado com sucesso, visto que este leva ao atraso na realização de todas as atividades. Através da análise dos projetos do PII desenvolvidos pela UFMG, destacam-se recursos financeiros como um motivo muito comum para o "congelamento" do projeto nos estágios de desenvolvimento da tecnologia e do negócio.
Destacam-se como exemplos dois projetos, o projeto da UFMG Vidros Bioativos, que se encontra na fase pré-comercial; e projeto de Poste Alternativo em Matriz Polimérica Reforçada por Fibras, fase comercial. No primeiro projeto, têm-se como fatores impeditivos o atraso na liberação de recursos que promoveu a não realização de alguns testes necessários, o que pode atrasar a comercialização. No segundo projeto, os recursos não foram liberados a tempo, o que atrasou $o$ desenvolvimento do produto. Além disso, quando se liberou o tempo exigido para consumi-los, isso foi pouco, dificultando a otimização dos gastos. Além disso, a flexibilidade por parte da organização com relação aos gastos foi baixa. 


\subsubsection{Recursos humanos e sociais}

Assim como ocorre na perspectiva de recursos financeiros, na perspectiva de recursos humanos e sociais os empreendedores também se deparam com um questionamento logo após a identificação da oportunidade: a equipe possui competências e habilidades internas e uma rede de contatos suficiente para iniciar o desenvolvimento da tecnologia?

A identificação dos recursos humanos e sociais necessários (Figura 15) para o desenvolvimento da tecnologia é considerada preponderante durante todas as fases que precedem o protótipo comercial do produto. Ou seja, o desenvolvimento do produto exige forte conhecimento técnico na área de pesquisa da EBT e, para tanto, é necessário o desenvolvimento da equipe interna e também a estruturação de uma rede de relacionamento para a troca de informações e experiências entre as pessoas. Pensando no desenvolvimento do negócio, a necessidade de internalização de recursos humanos em novas áreas de conhecimento se mostra latente: conhecimentos mercadológicos, comerciais, gerenciais, contábeis, jurídicos e em marketing, de forma a auxiliar na formatação do novo empreendimento tecnológico.

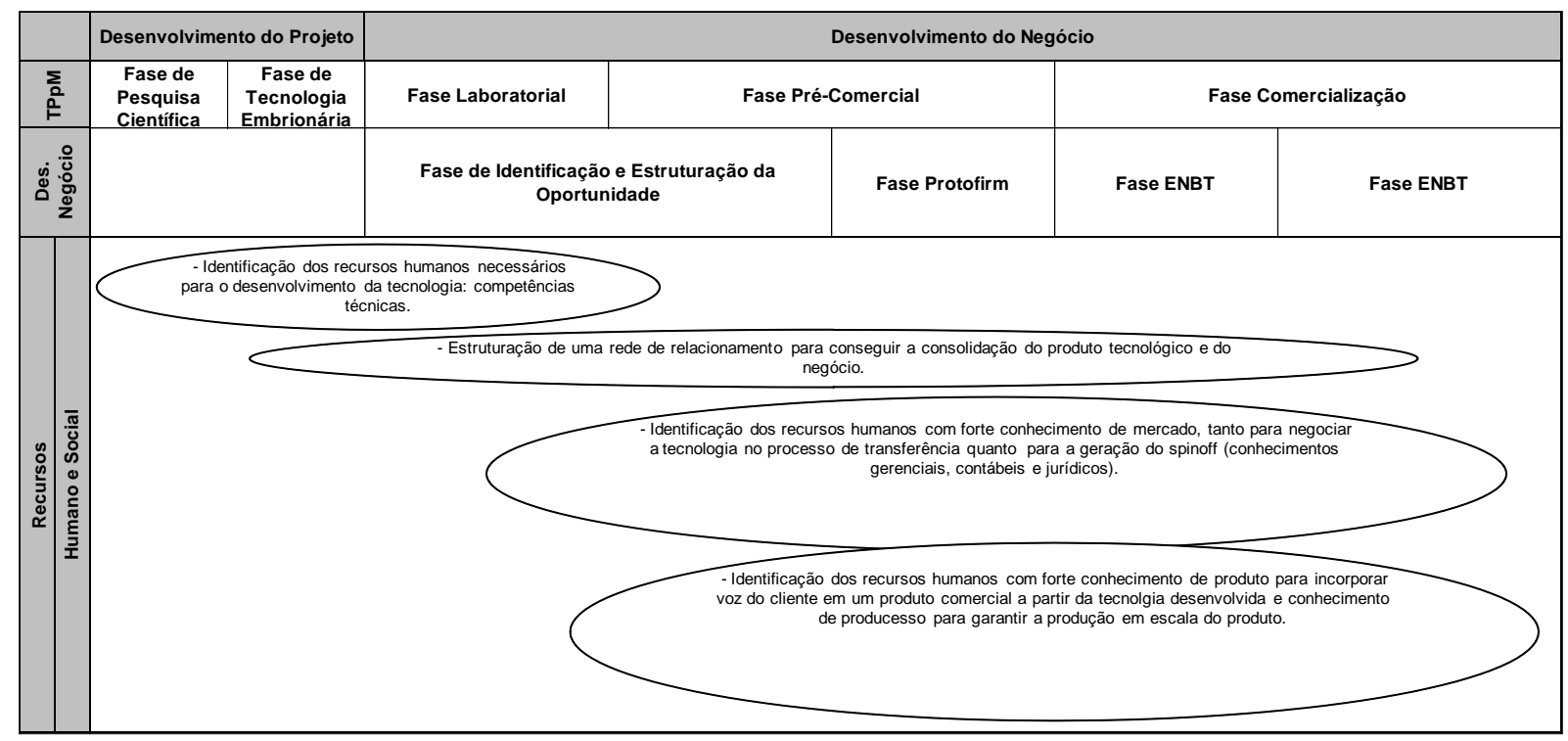

Figura 4 - Influência da dimensão humano/Social no processo de planejamento de negócio

Fonte: Os autores.

A intervenção dos bolsistas locais se mostrou menos proveitosa nos casos de projetos que se localizavam em estágio prematuro de desenvolvimento ao início da segunda fase do PII, uma vez que nesses projetos o grau de incerteza era relativamente grande para direcionar a pesquisa rumo a uma aplicação no mercado. Além disso, verificou-se que os pesquisadores possuem interesse em fornecer as informações e contribuir para com o trabalho. Sobre o suporte gerencial da equipe local, esse foi um fator facilitador no desenvolvimento do programa. Os bolsistas foram empenhados em sua grande maioria, havendo apenas algumas raras exceções, como nos casos de realização de outras atividades paralelamente à atuação no PII pelo bolsista, o que resultou em menor disponibilidade do bolsista para a execução das atividades relativas ao PII.

\subsubsection{Relação institucional}

$\mathrm{O}$ ambiente institucional no qual a ENBT está inserida é determinante no seu sucesso e, principalmente, na rapidez do desenvolvimento da empresa. A Figura 5 apresenta as necessidades de suporte e cultura institucional para a criação dos novos empreendimentos. Nas fases de pesquisa científica, tecnologia embrionária e fase laboratorial, é fundamental o incentivo das universidades e dos ICTs no que diz respeito a 
pesquisas, publicações e depósitos de patentes, já que esses são considerados os princípios para geração de valor através desses ICTs. Nessas fases, também é essencial a integração entre laboratórios, visando à identificação do estado da arte.

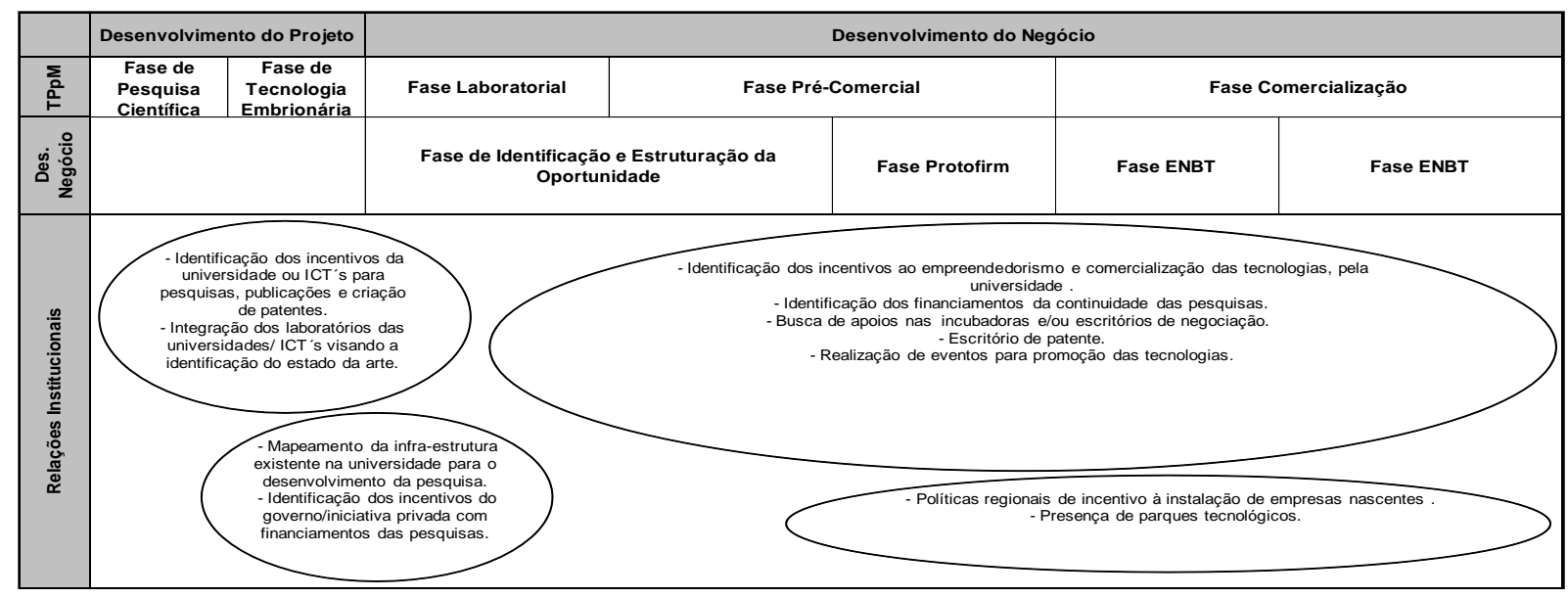

Figura 5 - Influência da perspectiva relações institucionais no processo de planejamento de negócio

Fonte: Os autores.

Durante o desenvolvimento do projeto, observa-se a importância de uma boa infraestrutura laboratorial, que possibilite o desenvolvimento da pesquisa. Para tanto, faz-se necessário incentivo financeiro de instituições governamentais ou privadas.

No decorrer do desenvolvimento do negócio, os principais fatores impulsionadores para a geração de EBTs de sucesso são: identificação de incentivos ao empreendedorismo e comercialização das tecnologias pela universidade, identificação dos financiamentos para a continuidade das pesquisas, presença de incubadoras e, ou, escritórios de negociação, apoio de escritórios de patentes e realização de eventos para a promoção das tecnologias. Por fim, já na fase comercial é importante que na região do entorno da "universidade-mãe" sejam identificados incentivos à instalação de empresas nascentes, além da presença de parques tecnológicos, os quais são os responsáveis por aproximar uma empresa advinda do ambiente acadêmico das dificuldades encontradas no mercado.

A burocracia das instituições deve ser lembrada como fator impeditivo para o desenvolvimento dos projetos, a complexidade da estrutura organizacional das universidades dificulta a eficiência da gestão e a eficácia dos procedimentos e normas. No projeto da UFMG de nanopartículas, o processo de compra burocrático, a impossibilidade de mudanças dentro dos itens inicialmente propostos no orçamento e a adaptação do projeto a novas oportunidades dificultaram o avanço do projeto no aspecto de conhecimento de mercado e planejamento.

\section{Considerações finais}

Este artigo identificou a influência das perspectivas institucional e de recursos (financeiro e humano/social) durante a integração TPM e, para isso, foram desdobradas as informações e necessidades de recursos financeiros, de competências e habilidades dos envolvidos, além do tipo de apoio institucional necessário para que o pesquisador-empreendedor possa evoluir no PPN. Dessa maneira, este estudo buscou explicitar algumas experiências importantes para o processo empreendedor e, com isso, auxiliar tanto os pesquisadores-empreendedores quanto os facilitadores do processo inovativo, oriundos do ambiente acadêmico, na difícil tarefa de transformar tecnologias desenvolvidas nos laboratórios de pesquisa em produtos e negócios viáveis técnica e economicamente.

Como resultado, espera-se obter um método sistemático para a identificação de FCSs em PIIs, bem como fatores que possuem influência negativa sobre o seu sucesso. Este método poderá ser convertido em uma sequência de passos essenciais na elaboração de propostas de PII e pontos para o seu julgamento. Não obstante, esse projeto poderá 
contribuir para uma melhor alocação de recursos em projetos de inovação tecnológica, bem como referência no intuito de aumentar as chances de sucesso de empreendimentos de base tecnológica.

\section{Referências}

BARDIN, L. Análise de conteúdo. Lisboa, Portugal: Edições 70, 1977.

FREMAN, C.; SOETE, L. The economics of industrial innovation. Routledge, 1997.

GALUNIC, D. C.; RODAN, S. Resource combinations in the firm: Knowledge Structures and the Potential for Schumpeterian Innovation. Strategic Management Journal, v. 1 19, n. 2, p. 473-496, 1998.

GOODAL, J. C.; KURATKO, D. F.; HORNSBY, J. S.; COVIN, J. G. Operations management and corporate entrepreneurship: The moderating effect of operations control on the antecedents of corporate entrepreneurial activity in relation to innovation performance. Journal of Operations Management, v. 29, i.1-2, p.116-127, jan. 2011.

GROSSMAN, G. M. Innovation and growth in the global economy. Cambridge: The MIT Press Cambridge, MA, 1993.

HAN, J. K.; KIM, N.; SRIVASTAVA, R. K. Market orientation and organizational performance: is innovation the missing link? Journal of Marketing, v. 62, p. 30-45, 1998.

HEIRMAN, A.; CLARYSSE, B. How and why do research-based start-ups differ at fouding? A resource-based configurational perspective. Journal of Technology Transfer, 2004.

LAHIRI, N. Geographic distribution of R\&D activity: how does it affect innovation quality? The Academy of Management Journal, v. 53, n. 5, oct. 2010.

LEE, C.; LEE, K.; PENNINGS, J. M. Internal capabilities, external networks, and performance: a study of technology- based ventures. Strategic Management Journal, v. 22, p. 615-640, 2001.

MAHMOOD, I.; MITCHELL, W. Two faces: effects of business groups on innovation in emerging economies. Management Science, v. 50, n. 10 , p.1348-1365, oct. 2004.
MUSTAR et al. Conceptualising the heterogeneity of research-based spin-offs: A multi-dimensional taxonomy. Research Policy, v. 35, p. 289-308, 2006.

PHELPS, C. C. A longitudinal study of the influence of alliance network structure and composition on firm exploratory innovation. The Academy of Management Journal, v. 53, n.4, aug. 2010.

ROBERTS, E. B. Entrepreneurs in high technology: Lessons from MIT and beyond. New York: Oxford University Press, 1991. Chap. 3, p. 46-99.

ROCKART, John. Chief executives define their own data needs. Harvard Business Review, v. 57, p 81-83, march.-apr. 1979.

SHANE, S. Academic entrepreneurship. Chaeltenhan, UK: University Spinoffs and wealth creation; Case Western Reserve University; New Horizons in Entrepreneurship, 2004.

SIMON, H. A. Comportamento administrativo: Estudo dos processos decisórios nas organizações administrativas. Rio de Janeiro: Fundação Getúlio Vargas, Instituto de Documentação, Serviço de Publicações, 1970.

VERGARA, S. C. Projetos e relatórios de pesquisa em administração. 6. ed. São Paulo: Atlas, 2005.

WRIGHT, M.; CLARYSSE, B.; LOCKETT, A. KNOCKAERT, M. Midrange Universities Linkages With Industry: Knowledge Types and The Role of Intermediaries. Research Policy, 2008.

Artigo selecionado entre os 10 melhores do

VIII Encontro Mineiro de Engenharia de Produção - EMEPRO 2012. 